\title{
A call for action to improve access to care and treatment for patients with rare diseases in the Asia-Pacific region
}

\author{
Swee-Sung Soon ${ }^{1}$, Gilberto Lopes ${ }^{2}$, Hwee-Yong Lim³ ${ }^{3}$ Durhane Wong-Rieger ${ }^{4}$, Salmah Bahri ${ }^{5}$, Lucy Hickinbotham , \\ Anand Jha ${ }^{6}$, Bor-Sheng Ko ${ }^{7}$, Diana MacDonell ${ }^{8}$, Jasmine Roah-Fang Pwu ${ }^{9}$, Ruby Shih ${ }^{10}$, Ekaphop Sirachainan ${ }^{11}$, \\ Dong-Churl Suh ${ }^{12}$, Janet Wale ${ }^{13}$, Xiao Zhang ${ }^{14}$ and Hwee-Lin Wee ${ }^{{ }^{*}}$
}

\begin{abstract}
This article is a call for action to the relevant stakeholders to improve access to care and treatment for patients with rare diseases in the Asia-Pacific region by looking into three main areas: (a) developing legislative definitions to confer enforceable protection, (b) creating or strengthening policies by objectively measuring the impact brought about by rare diseases and establishing platforms to reach out to the rare disease community, and (c) fostering collaboration across sectors and countries. It is hoped that these suggested actions can catalyze discussions and progress in the region.
\end{abstract}

Keywords: Challenges, Policy, Access to care, Asia-Pacific region

\section{Letters to the editor}

Dear Editor,

Despite many healthcare improvements in the AsiaPacific region, patients with rare diseases are still falling through the cracks. Many healthcare systems tend to consider each rare disease no differently from other more common diseases although these patients face a greater risk of being marginalized [1,2]. Based on the World Health Organization's prevalence estimate, collectively, rare diseases can affect 292 million people in the Asia-Pacific region [3].

Faced with uneven access to care and treatment of rare diseases, we wish to highlight (a) legal framework, (b) healthcare policy, and (c) collaborations as the three areas where rare disease patients in the region can benefit most. We are aware that separate considerations may be required for rare diseases that are treatable versus those that are not. However, for this letter, we would like to make a collective call for action for all types of rare diseases.

\footnotetext{
* Correspondence: phawhl@nus.edu.sg

${ }^{1}$ Department of Pharmacy, National University of Singapore, 18 Science Drive 4, 117543 Singapore, Singapore

Full list of author information is available at the end of the article
}

Developing legal definitions for terms such as "orphan drugs" and "rare disease" is pivotal to setting up legal frameworks to protect the well-being of the rare disease community. Looking to Taiwan, the Rare Disease Control and Orphan Drug Act brings significant economic relief to patients with genetic rare diseases through subsidies or reimbursement [4]. Despite the power that legislation wields, the long and arduous journey towards passing a bill can prompt one to look for non-legislative alternatives. Thailand stands out in the region because even without a legislative framework for rare diseases or orphan drugs, working definitions culminated in the inclusion of the Orphan Drug List into the National Drug List in 2012 [5]. While the lack of a legislative framework could still achieve some operative success, only the law can confer enforceable protection uniformly across the country, thus avoiding abrupt policy changes or postcode lottery situations.

Policy-wise, reaching out and understanding the rare disease community are primary steps to identifying inadequacies in existing systems. In Europe, the European Organisation for Rare Diseases (EURORDIS) led a survey program that lent many insights to the predicament of the rare disease community [6], and has important implications in policy formulation. Information-gathering initiatives like 
this should be considered in the Asia-Pacific region. The European Union Committee of Experts on Rare Diseases (EUCERD) later established with a mandate to formulate and implement activities in rare diseases [7] illustrates how a multi-national cross-sector panel can organize and implement rare disease initiatives. A 'EUCERD'-equivalent for the region can raise the awareness and commitment of policy-makers to act. To reach out to the community, the Taiwan Foundation for Rare Disorders represents patients with rare diseases in Taiwan before the policy-makers [8], showcasing a model suitable for smaller countries; in bigger countries, the National Organization for Rare Disorders presents another model as an alliance of individual patient groups [9]. Pooling previously fragmented groups on a national level can generate the much-needed awareness to overcome the lack of political will.

For implementation, a coordinated and pragmatic approach should be considered. As tackling rare diseases is resource-intensive, concerted efforts should be channeled to meet a need without duplication. To this, several European countries have launched defined national strategies on rare diseases [10]. Drawing from Europe's experience, the European Commission had been a vital catalyst in elevating awareness and coordinating information exchanges. These brought visibility to the rare disease community on the policy table. The high-level approach taken by the European Commission has galvanized policy-level support and a similar approach should be considered in the Asia-Pacific region. Having a taskforce to champion this cause will be a useful starting point.

Collaboration is key to advancing care for patients with rare diseases. Funded by a technology grant, South Korea's Rare Disease Knowledge Base showcases successful inter-agency collaboration by linking genetic, clinical and administrative databases to mitigate misdiagnosis. To be acquainted with global developments in rare diseases, platforms such as the Global Rare Diseases Patient Registry Data Repository (GRDR) and the International Rare Diseases Research Consortium (IRDiRC) can be explored. Countries stand to benefit from GRDR's existing data elements and open-source patient registry templates [11]. To facilitate the generation and exchange of data, countries in the region should actively contribute to existing registries [12], or consider starting registries for diseases unique to the region. On the research front, the IRDiRC links researchers and organizations investing in rare diseases research [13]. Of the 36 IRDiRC member organizations, only four were from the Asia-Pacific region, highlighting opportunities for the region to step up especially for diseases unique to the region.

In conclusion, we have identified three areas that warrant attention and action from relevant stakeholders to improve access to care and treatment for patients with rare diseases in the Asia-Pacific region. Several initiatives offer good examples to emulate but progress across the region is variable and more can be done through developing legislative definitions, strengthening rare disease policies, and fostering stronger collaboration.

\section{Abbreviations}

EUCERD: European Union Committee of Experts on Rare Diseases; EURORDIS: European Organisation for Rare Diseases; GRDR: Global Rare Diseases Patient Registry Data Repository; IRDiRC: International Rare Diseases Research Consortium.

\section{Competing interests}

The organization of the Asian Expert Forum for Rare Diseases (15-16 June 2013, Seoul), held in conjunction with the 10th Annual Meeting of Health Technology Assessment International (HTAi) 2013, was funded by Novartis Asia Pacific Pharmaceuticals Pte. Ltd. The funds covered the meeting venue cost, event secretariat support, and two nights' accommodation for each participant outside of South Korea. All authors attended the forum. HW, GL, and $\mathrm{HL}$ attended the forum in the capacity of Co-Chairpersons. Support for the meeting was to encourage dialogue for general access challenges of care and treatment for rare diseases in the region without driving any specific agenda. LH and AJ participated in the panel discussions to share insights from the perspective of the pharmaceutical industry. All authors had no other competing interest to declare in connection with this article.

\section{Authors' contributions}

All authors agreed to have the proceedings of the Expert Forum contribute to this study. HW and SS were involved in the initial conceptualization of this paper. SS, GL, HL, HW, LH, AJ provided critical input to the development of the paper. SS was involved in the acquisition of data and the initial drafting of the paper. All authors were involved in the subsequent revisions, and had read and approved the final paper.

\section{Acknowledgements}

The organization of the Asian Expert Forum for Rare Diseases (15-16 June 2013, Seoul) was funded by Novartis Asia Pacific Pharmaceuticals Pte. Ltd. The facilitation and overall management of its organization was conducted by Mudskipper Business Consulting (Shanghai) Limited. All authors attended the forum. HW, GL and HL attended the forum in the capacity of Co-Chairpersons. The funds covered the meeting venue cost, event secretariat support, two nights' accommodation for each overseas participant. Support for the meeting was to encourage dialogue for general access challenges of care and treatment for rare diseases in the region without driving any specific agenda.

The publication fee of this article is supported using funds administered by the International Society for Pharmacoeconomics and Outcomes Research Singapore Chapter (ISPOR-S). These funds are the balance from a 2012 event (Asian Expert Forum for Oncology Drug Access) in Singapore that was supported by funds from Novartis Pharmaceuticals Asia Pacific Pte Ltd (USD39,000 in all, covering meeting venue cost, event secretariat support, one night's accommodation for each overseas participant, and USD1,000 per diem for each participant). ISPOR-S has no involvement in this article.

\section{Author details}

'Department of Pharmacy, National University of Singapore, 18 Science Drive 4, 117543 Singapore, Singapore. ${ }^{2} J o h n s$ Hopkins University School of Medicine, 733 North Broadway, 21205 Baltimore, MD, USA. ${ }^{3}$ Novena Cancer Centre, Mount Elizabeth Novena Specialist Centre, 38 Irrawaddy Road, 329563 Singapore, Singapore. ${ }^{4}$ Institute for Optimizing Health Outcomes, Toronto, Canada. ${ }^{5}$ Pharmaceutical Services Division, Ministry of Health, Block E1, E3, E6, E7 \& E10, Parcel E, Federal Government Administration Centre, 62590 Putrajaya, Malaysia. ${ }^{6}$ Novartis Oncology, 20 Pasir Panjang Road, \#10-25/28 Mapletree Business City, 117439 Singapore, Singapore. ${ }^{7}$ National Taiwan University Hospital, No.7, Zhongshan S. Road, Zhongzheng District, Taipei City 10002, Taiwan. ${ }^{8}$ Pharmaceutical Benefits Advisory, Bedford Park, Australia. ${ }^{9}$ Center for Drug Evaluation 1 F, No.15-1, Sec.1, Hangjou S. Road, Taipei, Taiwan. ${ }^{10}$ Division of Medical Review and Pharmaceutical Benefits, Bureau of National Health Insurance, No.140, Sec.3, Hsinyi Road, Taipei 10634, Taiwan. ${ }^{11}$ Department of Medicine, Ramathibodi Hospital, 34/1 Soi Saengsuksa School, Isarapap Road, 
Min Buri, Bangkok 10510, Thailand. ${ }^{12}$ College of Pharmacy, Chung-Ang University, 221 Heukseok-dong, Dongjak-gu, Seoul, South Korea. ${ }^{13} \mathrm{HTAi}$ Interest Group for Patient/Citizen Involvement in Health Technology Assessment, Melbourne, Australia. ${ }^{14}$ The Public Health School, Southeast University, 2 Sipailou Rd, 210096 Nanjing, China.

Received: 6 April 2014 Accepted: 21 August 2014

Published online: 16 September 2014

\section{References}

1. Yaneva M: Rare diseases and genetic discrimination. J IMAB Annu Proc (Scientific Papers) 2011, 17(1):116-119

2. Trama A, Mallone S, Ferretti S, Meduri F, Capocaccia R, Gatta G, group Rw: The burden of rare cancers in Italy: the surveillance of rare cancers in Italy (RITA) project. Tumori 2012, 98:550-558.

3. United Nations Economic and Social Commission for Asia and the Pacific (ESCAP): Statistical Yearbook for Asia and the Pacific 2013; 2013. 3 Dec 2013 edition.

4. Taiwan Foundation for Rare Diseases: How Specific Legislation for Rare Diseases and Orphan Drugs is Changing Life for Some Patients in Taiwan; 2009.

5. Food and Drug Administration: Thailand Government Gazette on Orphan Drugs; [http://www.nlem.in.th/sites/default/files/goverment_gazette_ orphan_55_27nov2012.pdf]

6. Kole A, Faurisson F, EURORDIS: The Voice of 12,000 Patients - Experiences and Expectations of Rare Disease Patients on Diagnosis and Care in Europe. France: EURORDIS, Impression Design; 2009.

7. About EUCERD - History. [http://www.eucerd.eu/?page_id=45]

8. Taiwan Foundation for Rare Diseases. [http://59.124.212.42/English/index.php]

9. National Organization for Rare Disorders. [http://www.rarediseases.org/]

10. van Weely S, Leufkens HGM: Background Paper 6.19 Rare Diseases (Update on 2004 Background Paper). In Priority Medicines for Europe and the World "A Public Health Approach to Innovation"; 2013.

11. Forrest $C B$, Bartek RJ, Rubinstein $Y$, Groft SC: The case for a global rare diseases registry. Lancet 2011, 377:1058-1059.

12. Gaucher Registry, ICGG. [https://www.registrynxt.com/Gaucher/Pages/ Home.aspx]

13. International Rare Diseases Research Consortium. [http://www.irdirc.org/]

doi:10.1186/s13023-014-0137-1

Cite this article as: Soon et al:: A call for action to improve access to care and treatment for patients with rare diseases in the Asia-Pacific region. Orphanet Journal of Rare Diseases 2014 9:137.

\section{Submit your next manuscript to BioMed Central and take full advantage of:}

- Convenient online submission

- Thorough peer review

- No space constraints or color figure charges

- Immediate publication on acceptance

- Inclusion in PubMed, CAS, Scopus and Google Scholar

- Research which is freely available for redistribution 